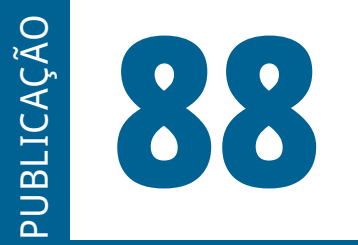

ISSN: 0101-9562

ISSN ELETRÔNICO: 2177-7055

SEQÜÊNCIA

Publicação do

Estudos jurídicos

e políticos

Programa de Pós-Graduação em Direito da UFSC

VOLUME 42 - ANO 2021 
SEQUÊNCIA - ESTUDOS JURÍDICOS E POLÍTICOS é uma publicação temática e de periodicidade quadrimestral, editada pelo Programa de Pós-Graduação Stricto Sensu em Direito da Universidade Federal de Santa Catarina - UFSC.

SEQUÊNCIA - ESTUDOS JURÍDICOS E POLÍTICOS is a thematic publication, printed every four months, edited by the Program in law of the Federal University of Santa Catarina - UFSC.

Versão eletrônica: http://www.periodicos.ufsc.br/index.php/sequencia

A publicação é indexada nas seguintes bases de dados e diretórios/

The Publication is indexed in the following databases and directories:

Base OJS

Base PKP

CCN (Catálogo Coletivo Nacional)

Dialnet

DOAJ (Directory of Open Access Journals)

EBSCOhost

Genamics Journalseek

ICAP (Indexação Compartilhada de Artigos de Periódicos)

Latindex

LivRe!

OJS
PKP
Portal de Periódicos UFSC
Portal do SEER
ProQuest
SciELO
Sherpa/Romeo
Sumarios.org
ULRICH'S
vLex

Ficha catalográfica

Seqüência: Estudos jurídicos e políticos. Universidade Federal de Santa Catarina.

Programa de Pós-Graduação em Direito. n.1 (janeiro 1980)-.

Florianópolis: Fundação José Boiteux. 1980-.

Publicação contínua

Resumo em português e inglês

Versão impressa ISSN 0101-9562

Versão on-line ISSN 2177-7055

1. Ciência jurídica. 2. Teoria política. 3. Filosoia do direito. 4. Periódicos.

I. Universidade Federal de Santa Catarina. Programa de Pós-graduação em

Direito

CDU 34(05)

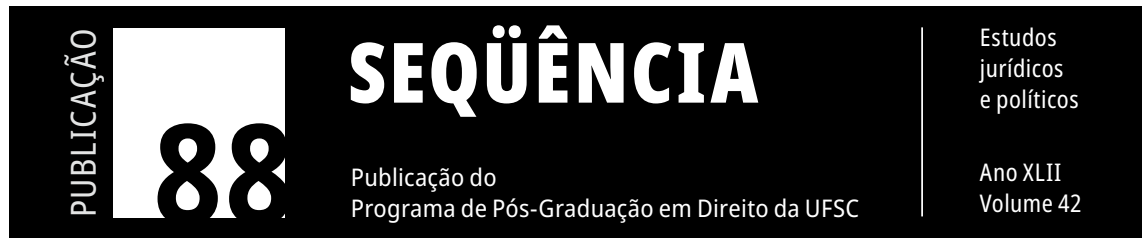




\title{
Silêncio na historiografia econômica brasileira: a legislação concorrencial como inovação institucional (1937-1945)
}

\author{
Silence in Brazilian economic historiography: competition \\ legislation as institutional innovation (1937-1945)
}

Mário André Machado Cabral New York University, New York, United States of America

RESUMO: O objeto do trabalho é investigar as legislações antitruste brasileiras dos anos 1930 e 1940. A hipótese é de que, a despeito do silêncio de relevantes autores da historiografia econômica brasileira, tais legislações e as instituições por elas criadas são inovações institucionais do primeiro período de Getúlio Vargas como Presidente (1930-1945), especificamente do Estado Novo (1937-1945). A partir de pesquisa bibliográfica e análise documental, os resultados apontaram que essa legislação representou uma inovação institucional. Concluiu-se que o legado jurídico-institucional do período inclui também o direito concorrencial.

PalaVRAS-CHAVE: Antitruste - Estado Novo - História do Direito Econômico.

ABSTRACT: The paper aims to investigate the Brazilian antitrust statutes from the 1930s and 1940s. The hypothesis is that, despite the silence of relevant authors of the Brazilian economic historiography, such statutes and the institutions created by them are legal and institutional innovations from Getúlio Vargas's first period as President (1930-1945), specifically the Estado Novo (1937-1945). Based on bibliographic research and documental analysis, the results indicated that such legislation represented an institutional innovation. The conclusion is that the legal and institutional legacy of the period also includes the competition law.

KEYWORDS: Antitrust - Estado Novo - History of Economic Law. 


\section{INTRODUÇÃO}

É comum se atribuir ao período 1930-1945 um conjunto de mudanças significativas nas funções e na estrutura do Estado brasileiro. Na esteira do movimento que alçou Getúlio Vargas à Presidência da República, a Revolução de 1930, mudanças importantes foram operadas: mudanças no perfil político das classes que ocuparam o poder; mudanças na forma de atuação do Estado perante a economia; mudanças constitucionais que abriram novos capítulos no constitucionalismo brasileiro; mudanças infraconstitucionais que refletiram novas preocupações estatais quanto a temas relevantes; mudanças institucionais que conferiram ao Estado novos instrumentos de intervenção, entre outras.

Dentre as mudanças, o presente trabalho tem como foco analisar as inovações jurídico-institucionais do período, isto é, o conjunto de instituições e diplomas normativos criados para dar conta das novas tarefas estatais, especialmente no campo econômico. O período foi responsável pela criação de ministérios, comissões, departamentos, institutos, empresas estatais, leis, além de duas Constituições. A historiografia costuma listar tais inovações. Contudo, raramente as legislações antitruste e as instituições criadas para sua implementação são incluídas como inovações institucionais do período.

Assim, o presente estudo pretende entender o sentido histórico das leis com conteúdo concorrencial do período, focando nos anos do Estado Novo (1937-1945), pois foi nesse período que surgiram as primeiras leis brasileiras com disposições tipicamente antitruste: o Decreto-Lei $n^{\circ}$ 869, de 18 de novembro de 1938, e o Decreto-Lei $n^{\circ}$ 7.666, de 22 de junho de 1945, conhecido como Lei Malaia. O objetivo é demonstrar que as legislações antitruste são inovações institucionais do período, tendo deixado legado observável nos dias atuais.

O texto se divide da seguinte maneira: primeiro, assinala-se a importância da Revolução de 1930 e da chegada de Vargas ao poder como um momento inaugural de importantes mudanças que se operariam nos 
anos seguintes no Estado brasileiro; segundo, são discutidas algumas das inovações jurídico-institucionais do período 1930-1945, focando-se no Estado Novo; por fim, analisam-se as primeiras legislações brasileiras com conteúdo antitruste e seu papel histórico, demonstrando sua compreensão como inovações institucionais do período.

\section{VARGAS E 0 ESTADO BRASILEIRO}

A partir da chegada de Getúlio Vargas ao Poder Executivo Federal como Presidente da República, em 1930, o Estado brasileiro passou por transformações. Com base na análise clássica de Celso Furtado, nota-se uma mudança da postura estatal no que concerne à atuação na economia, notadamente quanto ao gerenciamento dos efeitos da crise de 1929 e à defesa do setor cafeeiro. Diante da redução da demanda externa por café na esteira da crise e da importância do produto para o País, o governo resolveu expandir o crédito para financiar a retenção dos estoques. Furtado assinala a intervenção estatal nesse contexto como um verdadeiro programa de fomento da renda nacional: ao financiar o setor com recursos internos, conseguiu-se que o nível de renda não se corroesse e o emprego se mantivesse. Isso se deu sem contração de dívidas no exterior para financiar os estoques. Ainda que se aponte no mecanismo o que Furtado chama de "socialização das perdas" (toda a sociedade arcaria com o financiamento de um setor da economia), a expansão do crédito seria expressão de uma nova postura econômica estatal (FurTAdo, 2007, p. 263-273).

Outra mudança importante ocorrida na esteira da Revolução de 1930 foi quanto aos grupos político-sociais a ocuparem o poder. Antes dominado pela burguesia do café, o poder estatal passou a ser dividido, sob a mediação de Vargas, com outras frações de classe. Boris Fausto aponta para o fim da hegemonia da burguesia cafeeira seguida da constituição de um "Estado de compromisso", em que disputariam o espaço estatal grupos sociais distintos, como os setores 
agrário-exportador, especialmente o do café, a incipiente burguesia industrial e setores das classes médias, representadas, sobretudo, por grupos militares, que exerceram papel fundamental no movimento de 1930. Do ponto de vista ideológico, conforme Fausto, esse quadro político facilitou a emergência de formulações teóricas antiliberais e autoritárias que estão na base da instauração, anos depois, do Estado Novo e podem ser associadas também aos influxos de intervencionismo estatal na economia (FAusto, 1979, p. 104-114)1.

Octavio Ianni chega a assinalar que, com o triunfo da Revolução de 1930, o Estado passou a ser permeado por “conteúdos burgueses”. Isso não significa necessariamente a construção de um Estado liberal, mas aponta na direção da estruturação de um Estado com instituições político-econômicas e valores burgueses, em sentido amplo, superando um modelo estatal que exprimisse tão somente os interesses das oligarquias cafeeiras então dominantes. Nesse contexto, foram criadas diversas instituições para implementar novas missões estatais (IANNI, 1977, p. 13-24).

Sônia Draibe indica que as transformações do Estado brasileiro ocorreram a partir de três aparelhos centralizados do Estado: o "coercitivo-repressivo" - pertinente ao sistema judiciário e ao fortalecimento das Forças Armadas; o "social" - referente à incorporação como tarefas estatais relevantes temas como educação, saúde, previdência, entre outros; e o "econômico" - relacionado à criação de instituições que dizem respeito ao que Draibe chama de "ossatura material do Estado", expressando profunda intervenção do Estado na economia. Ao mesmo tempo em que se nota um fortalecimento

Com Bercovici, pode-se sublinhar que a construção de um Estado interventor começa se dar a bem antes do Estado Novo e antes, inclusive, da Constituição de 1934, por força de decisões do Poder Executivo Federal. Exemplos desse intervencionismo logo nos primeiros anos de Vargas no poder são a criação de novos ministérios, como o Ministério dos Negócios da Educação e Saúde Pública (Decreto n ${ }^{\circ}$ 19.402, de 14 de novembro de 1930) e o Ministério do Trabalho, Indústria e Comércio (Decreto $\mathrm{n}^{\circ}$ 19.433, de 26 de novembro de 1930), o Código de Minas (Decreto n 24.642, de 10 de julho de 1934) e o Código de Águas (Decreto n 24.643, de 10 de julho de 1934). BERCOVICI, 2009, p. 725-728. 
do Poder Executivo Federal e da figura de Vargas, parte das novas tarefas estatais é atribuída a instituições estatais descentralizadas, com base em criações legais inéditas (Draibe, 1985, p. 63-100).

Tais alterações institucionais se explicam pela necessidade de o Estado inovar para cumprir suas novas formas de atuação. Essas novas formas de atuação se manifestaram pela criação de instituições que explicitaram as transformações do Estado brasileiro no período pós1930. É o que se passa a discutir no tópico seguinte.

\section{INOVAÇÕES INSTITUCIONAIS DO PERÍODO 1930-1945}

Importantes autores se propuseram a listar e discutir as inovações institucionais surgidas no período 1930-1945. Pela relevância de suas contribuições, quatro autores serão aqui discutidos: Octavio Ianni, Eli Diniz, Sônia Draibe e Pedro Dutra Fonseca.

Octavio Ianni, em Estado e Planejamento Econômico no Brasil (1930-1970) (1971), enfatiza que, a partir de 1930, o Estado brasileiro passou a adotar medidas econômicas e inovações institucionais que simbolizaram as mudanças no relacionamento entre Estado e economia que marcaram o período ${ }^{2}$.

A ação do Poder Público, capitaneado por Vargas, incluiu a criação de diversas entidades e leis e a promoção de debates, entre distintos agentes, por vezes com interesses díspares, sobre as questões nacionais. Ianni faz uma lista das iniciativas estatais do período 1930-1945 que traduzem a preocupação do governo com a análise dos problemas nacionais, notadamente os econômicos, e a tomada de medidas para solucioná-los:

2 "Nos anos de 1930 a 1945, o governo brasileiro, sob Getúlio Vargas, adotou uma série de medidas econômicas e realizou inovações institucionais que assinalaram, de modo bastante claro, uma fase nova nas relações entre o Estado e o sistema político-econômico". IANNI, 1977, p. 14. 
1930: Ministério do Trabalho, Indústria e Comércio. 1931: Conselho Nacional do Café, Instituto do Cacau da Bahia. 1932: Ministério da Educação e Saúde Pública. 1933: Departamento Nacional do Café, Instituto do Açúcar e do Álcool. 1934: Conselho Federal do Comércio Exterior, Instituto Nacional de Estatística, Código de Minas, Código de Águas, Plano Geral de Viação Nacional, Instituto de Biologia animal. 1937: Conselho Brasileiro de Geografia, Conselho Técnico de Economia e Finanças. 1938: Conselho Nacional do Petróleo, Departamento Administrativo do Serviço Público (DASP), Instituto Nacional do Mate, Instituto Brasileiro de Geografia e Estatística (IBGE). 1939: Plano Nacional de Obras Públicas e Aparelhamento da Defesa. 1940: Comissão de Defesa da Economia Nacional, Instituto Nacional do Sal, Fábrica Nacional de Motores. 1941: Companhia Siderúrgica Nacional, Instituto Nacional do Pinho. 1942: Missão Cooke, Serviço Nacional de Aprendizagem Industrial (SENAI). 1943: Coordenação de Mobilização Econômica, Companhia Nacional de Álcalis, Fundação Brasil Central, Usina Siderúrgica de Volta Redonda, Consolidação das Leis do Trabalho, Serviço Social da Indústria (SESI), Plano de Obras e Equipamentos, I Congresso Brasileiro de Economia. 1944: Conselho Nacional de Política Industrial e Comercial, Serviço de Expansão do Trigo. 1945: Conferência de Teresópolis, Superintendência da Moeda e do Crédito (SUMOC), Decreto-Lei $N^{\circ} 7.666$, sobre atos contrários à ordem moral e econômica (IANNI, 1977, p. 23-24).

Duas observações se mostram pertinentes para a discussão ora endereçada. Primeiro, Ianni destaca não só as entidades criadas, mas também os diplomas normativos elaborados, como atestam as menções ao Código de Minas, ao Código de Águas, à Consolidação das Leis do Trabalho (CLT) e ao Decreto-Lei no 7.666/1945. Segundo, nenhuma menção é feita ao Decreto-Lei no 869/1938, que é considerado a primeira lei com disposições antitruste - anterior, portanto, ao Decreto-Lei no 7.666/1945.

Eli Diniz, em Empresário, Estado e Capitalismo no Brasil: 19301945 (1978), ao discutir a clássica controvérsia sobre o planejamento 
econômico, ocorrida nos anos de 1944 e 1945, entre Roberto Simonsen e Eugênio Gudin , aborda o que nomeou de "órgãos de supervisão e coordenação das atividades econômicas". Apesar de entender que os debates travados no interior do Estado acerca do tema do planejamento não apresentaram maiores resultados, Diniz nota que o saldo de tais debates e das iniciativas de criar instituições para discutir os grandes temas econômicos nacionais permite conhecer a orientação do governo com vistas a engendrar mecanismos de coordenação e intervenção do Estado na economia ${ }^{4}$.

Para endereçar as preocupações pertinentes à coordenação, pelo Estado, da situação econômica do País, Diniz aponta algumas das instituições que foram criadas:

Podemos situar como reflexo dessa preocupação a criação de órgãos, como o Conselho Federal de Comércio Exterior (CFCE), a Coordenação da Mobilização Econômica (CME), o Conselho Nacional de Política Industrial e Comercial (CNPIC) e a Comissão de Planejamento Econômico (CPE) (Dinız, 1978, p. 202).

A autora não cita as iniciativas de natureza antitruste conduzidas pelo governo, como o Decreto-Lei no 869/1938, que conferiu competência a uma instituição estatal, o Tribunal de Segurança

Sobre a controvérsia do planejamento entre Simonsen e Gudin, ver e.g.: MAGALHÃES; RODRIGUES, 2005; MARCOVITCH, 2009, p. 213-215.

4 "Efetivamente, uma análise mais profunda revela que esse período se caracterizou por um amplo debate em torno da idéia de 'planificação nacional', através do qual confrontaram-se posições doutrinárias distintas e até contraditórias, como expressão das várias correntes representadas na estrutura do poder.

Grande parte das propostas e projetos oriundos desta discussão não seriam postos em prática pelo embate de forças em confronto. Em conseqüência, os resultados concretos não tiveram maior significação. Entretanto, o saldo resultante, em termos das sugestões encaminhadas e dos órgãos criados, indica uma linha de orientação bastante definida do Governo federal, no sentido de estabelecer mecanismos de coordenação econômica, dando à intervenção do Estado na economia uma dimensão mais abrangente e integrada". DINIZ, 1978, p. 201. 
Nacional (TSN), para reprimir os crimes contra a economia popular, e o Decreto-Lei $n^{\circ}$ 7.666/1945, que previu a criação de um órgão, a Comissão Administrativa de Defesa Econômica (C.A.D.E.), com a atribuição de combater práticas de abuso do poder econômico.

Sônia Draibe observa que a montagem do aparelho econômico estatal entre 1930 e 1945 obedeceu a um duplo princípio: centralização dos comandos e descentralização funcional ou administrativa. A instituição dotada da atribuição de racionalizar a burocracia estatal foi o Conselho Federal do Serviço Público, criado em 1936 e substituído em 1938 pelo Departamento Administrativo do Serviço Público (DASP). Entretanto, o DASP não teria como tarefa a discussão e coordenação, pelo Estado, das políticas econômicas a serem implementadas. Para tais tarefas, foram criados órgãos de distintas naturezas para debater e instaurar políticas como a cambial e de comércio exterior, a monetário-creditícia e a de seguros. Sem seguir uma ordem cronológica, Draibe cita: (i) quanto à questão monetário-creditícia e cambial, a Superintendência da Moeda e do Crédito (Sumoc), de 1945; a Carteira de Exportação e Importação do Banco do Brasil (Cexim), de 1941; a Carteira de Crédito Agrícola e Industrial do Banco do Brasil, de 1937; o Banco de Crédito da Borracha, de 1942; a Comissão de Financiamento da Produção, de 1943; e a Comissão de Investimento, de 1944; (ii) quanto à questão dos seguros, o Departamento Nacional de Seguros Privados e Capitalização, no Ministério do Trabalho, Indústria e Comércio, de 1934; e o Instituto de Resseguros do Brasil, de 1940; (iii) quanto à questão do fomento da produção e comercialização, sobretudo de itens agroindustriais, o Departamento Nacional do Café, de 1933; o Instituto Nacional do Açúcar e do Álcool, de 1933; o Instituto Nacional do Mate, de 1938; o Instituto Nacional do Pinho, de 1941; o Instituto Nacional do Sal, de 1941; e o Instituto do Cacau da Bahia, de 1931; (iv) quanto à questão dos recursos naturais, o Departamento Nacional da Produção Mineral (DNPM), de 1934;

o Conselho Nacional do Petróleo, de 1938; o Conselho de Águas 
e Energia Elétrica, de 1939; e o Conselho Nacional de Minas e Metalurgia, de 1940; (v) quanto à questão industrial, a Comissão Executiva do Plano Siderúrgico Nacional, de 1940; a Comissão Executiva Têxtil, de 1942; a Comissão Nacional de Combustíveis e Lubrificantes, de 1941; a Comissão Nacional de Ferrovias, de 1941; a Comissão Vale do Rio Doce, de 1942; e a Comissão da Indústria de Material Elétrico, de 1944 (Draibe, 1985, p. 84-90).

A esses órgãos, voltados para matérias ou setores específicos, Draibe adiciona instituições responsáveis por áreas mais amplas, com caráter consultivo, normativo ou deliberativo: o Conselho Federal do Comércio Exterior (CFCE), de 1934; o Conselho Técnico de Economia e Finanças (CTEF), de 1937; o Conselho da Economia Nacional, que contava com previsão na Constituição de 1937, mas não chegou a ser criado; a Coordenação da Mobilização Econômica, de 1942, criada no contexto da Segunda Guerra Mundial; o Conselho Nacional de Política Industrial e Comercial, de 1944; e a Comissão de Planejamento Econômico, também de 1944 (Draibe, 1985, p. 90-92).

No que concerne especificamente às relações de trabalho, Draibe menciona como criações institucionais: o Ministério do Trabalho, Indústria e Comércio, de 1931; o Conselho de Imigração e Colonização, de 1938; e a CLT, de 1943. A CLT não foi o único instrumento normativo citado pela autora como inovação institucional. Draibe lista outras iniciativas legislativas: o Código de Águas e o Código de Minas, de 1934; a regulamentação dos Serviços de Radiocomunicações em Território Nacional, entre 1931 e 1934; o Código Brasileiro do Ar, de 1938; o Código de Caça e Pesca e o Código Florestal, de 1934. Draibe cita, ainda, genericamente, outras iniciativas legais, como o Código da Propriedade Industrial, a Lei das Sociedades por Ações e o Anteprojeto do Código de Obrigações (Draibe, 1985, p. 92-94).

Draibe menciona também, acerca da centralização dos instrumentos de informação estatística do governo, o Conselho Brasileiro 
de Geografia, de 1933, e o Instituto Nacional de Estatística, de 1934, transformado, em 1938, no Instituto Brasileiro de Geografia e Estatística (IBGE) (Draibe, 1985, p. 96-97).

Apesar do quadro amplo traçado por Draibe, as legislações com conteúdo concorrencial e as instituições relacionadas a essas legislações não são mencionadas pela autora.

Para Pedro Dutra Fonseca, em Vargas: o capitalismo em construção (1987), o intervencionismo na economia se aprofunda a partir de 1937 e apresenta como objetivo alcançar o desenvolvimento econômico, notadamente via industrialização. A ideia de desenvolvimento econômico passou a pautar toda a retórica e a ação governamentais, desde as mudanças institucionais ao fomento de determinados setores ${ }^{5}$.

Tratando das "ações governamentais pró-desenvolvimento", Fonseca assinala que o governo possuía um projeto econômico marcado por intervencionismo e explicitado com a criação de diversas instituições estatais para lidar com o plano desenvolvimentista. O autor enumera da seguinte forma tais entidades:

Em 1938 criou-se o Conselho Nacional do Petróleo, o Departamento Administrativo do Serviço Público (DASP), o Instituto Nacional do Mate e o Instituto Brasileiro de Ge-

5 "É bem verdade que anteriormente, seja no início da década de 1930 ou ainda na República Velha, Vargas falava na necessidade do desenvolvimento econômico. Entretanto, somente a partir de 1937 este deixou de ser apenas uma idéia, ponto de um programa mais amplo, para tornar-se a pedra de toque de toda a ação governamental, justificando seus atos, as mudanças institucionais, o incentivo a determinados setores, a criação de determinados órgãos: com o Estado Novo, o 'intervencionismo conservador' positivista paulatinamente passou a ter a cara de um intervencionismo com compromisso com o futuro. Construir uma nação desenvolvida tornou-se o ponto principal da retórica governista, capaz de aglutinar em torno de si a expressiva maioria da nação". FONSECA, 1987, p. 256-257. Sobre o positivismo nas formulações varguistas, ver: LOVE, 1975; BOSI, 1992, p. 273-307; BOSI, 2013, p. 277-301; FONSECA, 2012a, p. 38-45. Sobre o estabelecimento de uma relação entre positivismo e intervenção econômica estatal via antitruste, ver: CABRAL, 2016, p. 223-227, CABRAL, 2020, p. 292-297. 
ografia e Estatística (IBGE). São de 1939 o Plano de Obras Públicas e Aparelhamento de Defesa e o Conselho de Águas e Energia. Em 1940 foram criados a Comissão de Defesa da Economia Nacional, o Instituto Nacional do Sal, a Fábrica de Motores e a Comissão Executiva do Plano Siderúrgico Nacional. Datam de 1941 a Companhia Siderúrgica Nacional, o Instituto Nacional do Pinho, a Comissão de Combustíveis e Lubrificantes e o Conselho Nacional de Ferrovias. O Serviço Nacional de Aprendizagem Industrial (SENAI) e a Comissão do Vale do Rio Doce são de 1942. O ano de 1943, além de marcar a elaboração da Consolidação das Leis do Trabalho, lembra a criação da Companhia Nacional de Álcalis, da Coordenação de Mobilização Econômica (CME), da Fundação Brasil Central, da Usina Siderúrgica de Volta Redonda, do Serviço Social da Indústria (SESI) e do Plano de Obras e Equipamentos. Em 1944 Vargas criou o Conselho Nacional de Política Industrial e Comercial, o Serviço Nacional do Trigo e a Comissão de Planejamento Econômico (CPE). Finalmente, em 1945 criou-se a Superintendência da Moeda e do Crédito (SUMOC) (Fonseca, 1987, p. 259) ${ }^{6}$.

Nota-se que Fonseca e os demais autores, apesar de discorrerem sobre as inovações institucionais do período e listarem uma série de entidades criadas na esteira do intervencionismo econômico estatal varguista, não mencionam as legislações antitruste ${ }^{7}$.

O que se pretende no próximo tópico é discorrer sobre essas legislações, de modo a verificar se os diplomas normativos com conteúdo jurídico-concorrencial, bem como as instituições a eles correlacionadas, podem ser considerados inovações institucionais e incluídas nas listas dos autores de referência que se debruçaram sobre o tema.

\footnotetext{
No mesmo sentido: FONSECA, 2012b, p. 173-174.

7 Ressalte-se que Ianni não menciona o Decreto-Lei no 869/1938, mas cita o Decreto-Lei $\mathrm{n}^{\mathrm{o}}$ 7.666/1945 (IANNI, 1977, p. 24). Edgar Carone, embora, diferentemente dos demais autores aqui tratados, não se ocupe de arrolar as inovações institucionais do período, faz menção a ambos os decretos: CARONE, 1976b, p. 67 e 84.
} 


\section{AS LEGISLAÇÕES ANTITRUSTE: INOVAÇÕES INSTITUCIONAIS}

\subsection{Os fundamentos constitucionais}

A Constituição de 1934 trouxe pela primeira vez um dispositivo que tratava de economia popular ${ }^{8}$. O sentido do fomento da economia popular pode ser entendido como a proteção do bem-estar econômico do povo contra atos de agentes com capacidade de alterar as condições normais de mercado. Não se confundia nem com "economia pública", nem com "economia privada"; tratava-se da manutenção das capacidades econômicas da coletividade ${ }^{9}$. Duas preocupações eram primordiais nesse contexto: altos preços e risco de desabastecimento. A ideia era de que o Estado, com o fomento da economia popular, deveria controlar e sancionar agentes que praticassem preços considerados abusivos e manipulassem a oferta de bens considerados essenciais, prejudicando o abastecimento ${ }^{10}$.

O fomento da economia popular foi reproduzido na Constituição de 1937, que estabeleceu que os crimes contra a economia popular seriam equiparados aos crimes contra o Estado ${ }^{11}$. O Decreto-Lei $n^{\circ}$ 869/1938 foi a regulamentação do art. 141 da Constituição de 1937.

8 “Art 117. A lei promoverá o fomento da economia popular, o desenvolvimento do credito e a nacionalização progressiva dos bancos de deposito. Igualmente providenciará sobre a nacionalização das empresas de seguros em todas as suas modalidades, devendo constituir-se em sociedades brasileiras as estrangeiras que actualmente operam no paiz".

9 Não por coincidência, a dicção da atual Lei de Defesa da Concorrência, a Lei no ${ }^{\circ} 12.529$, de 30 de novembro de 2011, traz como a titular dos bens jurídicos protegidos pela lei a coletividade: "Art. 1ำ [...] Parágrafo único. A coletividade é a titular dos bens jurídicos protegidos por esta Lei".

10 Sobre o sentido de economia popular na origem do antitruste brasileiro, cf. CABRAL, 2016, p. 51-57; CABRAL, 2018, p. 175-176; CABRAL, 2019, CABRAL, 2020, p. 71-78. Ver também: HUNGRIA, 1939, p. 8-18; LYRA FILHO, 1939, p. 17; LYRA FILHO, 1946, 10; LYRA, 1940, p. 91-96; OLIVEIRA, 1952, p. 9-21.

11 “Art. 141. A lei fomentará a economia popular, assegurando-lhe garantias especiaes. Os crimes contra a economia popular são equiparados aos crimes contra o Estado, devendo 


\subsection{Decreto-Lei ${ }^{\circ}$ 869/1938}

O Decreto-Lei $n^{\circ} 869 / 1938$ foi a primeira lei brasileira com disposições tipicamente antitruste ${ }^{12}$. O ministro da Justiça e Negócios Interiores responsável por sua criação foi Francisco Campos, e quem efetivamente elaborou o texto legal foi Nelson Hungria ${ }^{13}$. A competência para julgar os crimes contra a economia popular foi conferida ao Tribunal de Segurança Nacional (TSN). O TSN foi criado em 1936 pela Lei no 244, de 11 de setembro de 1936, como órgão da Justiça Militar, com competência para processar e julgar os "crimes contra a segurança da República" e os "crimes contra as instituições militares” (art. 3º. A Lei no 244/1936 foi modificada pelo Decreto-Lei n ${ }^{\circ} 88$, de 20 de dezembro de 1937, que, além de alterações procedimentais, incluiu como de competência do TSN os crimes: "contra a existência, a segurança e a integridade do Estado, contra a estrutura das instituições e contra a economia popular, a sua guarda e o seu emprego" (art. $4^{\circ}$ ). O Decreto-Lei no 869/1938 previu a competência do TSN para processar e julgar tais crimes contra a economia popular $\left(\text { art. } 6^{\circ}\right)^{14}$.

a lei cominar-lhes penas graves e prescrever-lhes processo e julgamento adequados á sua prompta e segura punição”.

12 Vários autores reconhecem esse fato: SHIEBER, 1966, p. 3-6; BULGARELLI, 1996, p. 118-119; CARONE, 1976b, p. 84-85; BARBIERI FILHO, 1984, 32-34; FRANCESCHINI; FRANCESCHINI, 1985, p. 7-9; FERRAZ JÚNIOR, 1992, p. 176-177; VAZ, 1993, p. 244-247; FONSECA, 2001, p. 44-47; SALGADO, 1997, p. 175; FORGIONI, 2012, p. 94-101; SALOMÃO FILHO, 2002, p. 72-73; PROENÇA, 2001, p. 25-27; OLIVEIRA; RODAS, 2004, p. 17-18; BERCOVICI, 2005, p. 24; BAGNOLI, 2005, p. 83-85; ONTO, 2009, p. 56-57; MARTINEZ, 2010, p. 13-15; BERCOVICI; ANDRADE, 2011, p. 450-452; CARVALHO, 2011, p. 18; PRADO, 2012, p. 100; NASCIMENTO, 2012, p. 187-188; TODOROV; TORRES FILHO, 2012, p. 213215; ANDRADE, 2014, p. 126-127; PFEIFFER, 2015, p. 130-131; CABRAL, 2016, p. 57; MIOLA, 2016, p. 648; PEREIRA NETO; CASAGRANDE, 2016, p. 21-22; FRAZÃO, 2017, p. 33-35, CABRAL, 2020, p. 78-79.

13 Cf. CÂMARA DOS DEPUTADOS, 1956, p. 1191.

14 Sobre o TSN, ver: SILVA, 2007, p. 273-303; CAMPOS, 1982; BALZ, 2009. 
O decreto se insere em um quadro maior de iniciativas interventivas do governo com vistas à promoção do desenvolvimento. Campos, ao trazer a público a justificativa do decreto, assinalou que a lei tinha dois objetivos principais. O primeiro seria a promoção da proteção da economia popular. O bom emprego da economia popular possibilitaria a formação das reservas econômicas necessárias à "expansão das empresas e indústrias úteis". A segunda finalidade do decreto seria "evitar o bloqueio da concorrência". A livre competição seria fundamental ao "desenvolvimento industrial e comercial do País" (CAmpos, 1939, p. 191). Percebe-se, nesse sentido, que o fomento da economia popular e da livre concorrência, com o Decreto-Lei $\mathrm{n}^{\circ}$ 869/1938, seria instrumental a fins maiores: a expansão das empresas e indústrias úteis e o desenvolvimento industrial e comercial do País. Isto é, tratava-se de mais um instrumento criado para alcançar os grandes objetivos econômicos da nação relacionados ao desenvolvimento econômico industrial do País, assim como as demais instituições e leis que foram mencionadas na seção anterior.

Quanto à tipificação de condutas como crimes contra a economia popular, a lista de ilícitos trazida pelo decreto incluía desde típicas práticas anticompetitivas, como preço predatório e fixação de preço de revenda, a ilícitos que não tinham natureza antitruste, como gestão fraudulenta e fraude a pesos e medidas ${ }^{15}$.

15 “Art. $1^{\circ}$ Serão punidos na forma desta lei os crimes contra a economia popular, sua guarda e seu emprego.

Art. $2^{\circ}$ São crimes dessa natureza:

I - destruir ou inutilizar, intencionalmente e sem autorização legal, com o fim de determinar alta de preços, em proveito próprio ou de terceiro, matérias primas ou produtos necessários ao consumo do povo;

II - abandonar ou fazer abandonar lavouras ou plantações, suspender ou fazer suspender a atividade de fábricas, usinas ou quaisquer estabelecimentos de produção, ou meios de transporte, mediante indenização paga pela desistência da competição;

III - promover ou participar de consórcio, convênio, ajuste, aliança ou fusão de capitais, com o fim de impedir ou dificultar, para o efeito de aumento arbitrário de lucros, a concorrência em matéria de produção, transporte ou comércio; 


\section{É importante notar que alguns desses dispositivos estão re- produzidos na atual lei brasileira de defesa da concorrência, a Lei $n^{\circ}$}

IV - reter ou açambarcar matérias primas, meios de produção ou produtos necessários ao consumo do povo, com o fim de dominar o mercado em qualquer ponto do país e provocar a alta dos preços;

$\mathrm{V}$ - vender mercadorias abaixo do preço de custo com o fim de impedir a concorrência;

VI - provocar a alta ou baixa de preços, títulos públicos, valores ou salários por meio de notícias falsas, operações fictícias ou qualquer outro artifício;

VII - dar indicações ou fazer afirmações falsas em prospectos ou anúncios, para o fim de subscrição, compra ou venda de títulos, ações ou quotas;

VIII - exercer funções de direção, administração ou gerência de mais de uma empresa ou sociedade do mesmo ramo de indústria ou comércio com o fim de impedir ou dificultar a concorrência;

IX - gerir fraudulentamente ou temerariamente bancos ou estabelecimentos bancários, ou de capitalização; sociedades de seguros, pecúlios ou pensões vitalícias; sociedades para empréstimos ou financiamento de construções e de vendas de imóveis a prestações, com ou sem sorteio ou preferência por meio de pontos ou quotas; caixas econômicas; caixas Raiffeisen; caixas mútuas, de beneficência, socorros ou empréstimos; caixas de pecúlio, pensão e aposentadoria; caixas construtoras; cooperativas; sociedades de economia coletiva, levando-as à falência ou à insolvência, ou não cumprindo qualquer das cláusulas contratuais com prejuízo dos interessados;

$\mathrm{X}$ - fraudar de qualquer modo escriturações, lançamentos, registos, relatórios, pareceres e outras informações devidas a sócios de sociedades civis ou comerciais, em que o capital seja fracionado em ações ou quotas de valor nominativo igual ou inferior a 1:000\$000, com o fim de sonegar lucros, dividendos, percentagens, rateios ou bonificações, ou de desfalcar ou desviar fundos de reserva ou reservas técnicas.

Pena: prisão celular de 2 a 10 anos e multa de 10:000\$000 a 50:000\$000.

Art. $3^{\circ}$ São ainda crimes contra a economia popular, sua guarda e seu emprego:

I - celebrar ajuste para impor determinado preço de revenda ou exigir do comprador que não compre de outro vendedor;

II - transgredir tabelas oficiais de preços de mercadorias;

III - obter ou tentar obter ganhos ilícitos, em detrimento do povo ou de número indeterminado de pessoas, mediante especulações ou processos fraudulentos ("bola de neve", "cadeias", "pichardismo", etc.);

IV - violar contrato de venda a prestações, fraudando sorteios ou deixando de entregar a coisa vendida, sem devolução das prestações pagas, ou descontar destas, nas vendas com reserva de domínio, quando o contrato fôr rescindido por culpa do comprador, quantia maior do que a correspondente à depreciação do objeto;

$\mathrm{V}$ - fraudar pesos ou medidas padronizados em lei ou regulamento; possuí-los ou detêlos, para efeitos de comércio, sabendo estarem fraudados.

Pena: prisão celular de 6 meses a 2 anos e multa de 2:00\$000 a 10:000\$000”. 
12.529/2011. O art. $2^{\circ}$, I e IV, do Decreto-Lei no 869/1938, pode ser associado ao art. $36, \mathbb{\$} 3^{\circ}$, XIII, da Lei ${ }^{\circ} 12.529 / 2011^{16}$. O art. $2^{\circ}$, III, Decreto-Lei $n^{\circ} 869 / 1938$, pode ser relacionado a práticas de coordenação horizontal, como o cartel (art. 36, \ $3^{\circ}$, I, da Lei no 12.529/2011), e a atos de concentração (art. 90, da Lei n ${ }^{\circ} 12.529 / 2011^{17}$ ). O art. $2^{\circ}$, V, do Decreto-Lei no 869/1938, tem redação quase idêntica a do art. $36, \S 3^{\circ}, X V$, da Lei $n^{\circ} 12.529 / 2011^{18}$. O art. $3^{\circ}$, I, apresenta redação próxima a do art. $36, \mathbb{S} 3^{\circ}$, IX, da Lei $n^{\circ} 12.529 / 2011^{19}$. Vê-se, desse modo, que o legado legal e institucional do Decreto-Lei no 869/1938 é notável até os dias de hoje em leis com a importância da Lei $n^{\circ}$ 12.529/2011.

Observe-se que a previsão desses tipos ilícitos, com conteúdo antitruste, foi algo inédito no Brasil. Pode-se, assim, falar em inovação institucional, com a criação de uma lei específica para tratar de matérias concorrenciais e com a atribuição a um órgão estatal, o TSN, para implementar a aplicação do decreto ${ }^{20}$.

16 “Art. $36[\ldots] \& 3^{\circ}[\ldots]$ XIII - destruir, inutilizar ou açambarcar matérias-primas, produtos intermediários ou acabados, assim como destruir, inutilizar ou dificultar a operação de equipamentos destinados a produzi-los, distribuí-los ou transportá-los".

17 “Art. 90. Para os efeitos do art. 88 desta Lei, realiza-se um ato de concentração quando: I - 2 (duas) ou mais empresas anteriormente independentes se fundem;

II - 1 (uma) ou mais empresas adquirem, direta ou indiretamente, por compra ou permuta de ações, quotas, títulos ou valores mobiliários conversíveis em ações, ou ativos, tangíveis ou intangíveis, por via contratual ou por qualquer outro meio ou forma, o controle ou partes de uma ou outras empresas;

III - 1 (uma) ou mais empresas incorporam outra ou outras empresas; ou

IV - 2 (duas) ou mais empresas celebram contrato associativo, consórcio ou joint venture".

18 "Art. $36[\ldots] \int 3^{\circ}[\ldots] \mathrm{XV}$ - vender mercadoria ou prestar serviços injustificadamente abaixo do preço de custo".

19 “Art. $36[\ldots] \mathbb{S} 3^{\circ}[\ldots]$ IX - impor, no comércio de bens ou serviços, a distribuidores, varejistas e representantes preços de revenda, descontos, condições de pagamento, quantidades mínimas ou máximas, margem de lucro ou quaisquer outras condições de comercialização relativos a negócios destes com terceiros".

20 Sobre a aplicação dos dispositivos antitruste do decreto pelo TSN, ver: CABRAL, 2016, p. 83-93; CABRAL 2018; CABRAL, 2020, p. 112-126. 


\subsection{Decreto-Lei $n^{0} 7.666 / 1945$}

O responsável pela elaboração do Decreto-Lei no 7.666/1945, também conhecido como Lei Malaia ${ }^{21}$, foi o então ministro da Justiça e Negócios Interiores Agamemnon Magalhães. Nos momentos finais do Estado Novo, elaborou-se uma lei especificamente antitruste, com a previsão de criação de uma instituição vocacionada à aplicação da legislação concorrencial, a Comissão Administrativa de Defesa Econômica (C.A.D.E.). Com essa lei, ter-se-ia um diploma normativo com conteúdo limitado ao direito concorrencial, a ser aplicado no âmbito da Administração Pública Federal, diferentemente do Decreto-Lei n ${ }^{\circ}$ 869/1938, que previa ilícitos antitruste, mas também outros desprovidos dessa natureza, e tinha caráter penal, a ser aplicado por autoridade judiciária especial (o TSN) com competência para processar outros tipos de delito além dos de caráter concorrencial ${ }^{22}$. O modelo articulado por Agamemnon Magalhães é o que permanece até hoje: uma lei somente com conteúdo antitruste e uma autoridade administrativa especializada em defesa da concorrência. A Lei no 12.529/2011 e o Conselho Administrativo de Defesa Econômica (Cade) são legados dessa concepção.

Assim como o Decreto-Lei n 869/1938, o Decreto-Lei $n^{\circ}$ $7.666 / 1945$ se insere em um conjunto de medidas adotadas pelo governo com o objetivo de alcançar os grandes objetivos nacionais, sintetizados na ideia de desenvolvimento econômico. Agamemnon Magalhães era um

21 Agamemnon Magalhães era chamado jocosamente de "malaio", em virtude de seus traços físicos ligeiramente orientais. Cf. MAGALHÃES, 1988, p. 11; FORGIONI, 2012, p. 103, nota de rodapé n ${ }^{\circ} 70$; CABRAL, 2016, p. 109, nota de rodapé no 264; CABRAL, 2020, p. 144-145.

22 À época da publicação da Lei Malaia, ainda estava em vigor o Decreto-Lei no 869/1938. Uma das críticas ao decreto de 1945 era que tratava de matéria já disciplina pelo decreto de 1938. Agamemnon Magalhães entendia que os diplomas tinham diferenças. Uma das principais diferenças era que a Lei Malaia dava à matéria tratamento administrativo, e não penal, como o Decreto-Lei n ${ }^{\circ}$ 869/1938. Ademais, o Decreto-Lei n ${ }^{\circ} 7.666 / 1945$ estabelecia a criação de um órgão técnico especializado. FGV/CPDOC, AGM c 45.06.00/1. 
crítico do laissez faire, entendendo caber ao Estado intervir na economia tendo em vista uma melhor distribuição da riqueza e o interesse social ${ }^{23}$. Nesse sentido, a ação de trustes e cartéis deveria ser combatida pelo Estado, pois prejudicaria os interesses da "nossa economia industrial" 24 . A preocupação com o desenvolvimento da economia nacional e, em particular, com a indústria nacional fica demonstrada em correspondência enviada pelo ministro a Vargas, em que o primeiro, submetendo ao Presidente uma espécie de projeto da Lei Malaia, registra que trustes locais e estrangeiros destruíram iniciativas industriais nacionais ${ }^{25}$. Era necessária, nesse contexto, uma legislação especificamente antitruste não só porque o combate ao abuso do poder econômico era urgente, mas também porque esse abuso era prejudicial ao desenvolvimento industrial do País ${ }^{26}$. Vê-se, pois, que o Decreto-Lei n ${ }^{\text {o }}$ 7.666/1945 era mais uma medida formulada com vistas a buscar os grandes objetivos econômicos nacionais, ao lado de tantas outras medidas listadas na seção anterior.

Nota-se, ainda, na Lei Malaia, um componente que alguns autores associaram a um nacionalismo econômico (IANNI, 1977, p. 61-63; BANDeira, 1975, p. 1-13; VAz, 1993, p. 248; Forgioni, 2012, p. 101-106; Carvalho, 2011, p. 18; Cabral, 2020, p. 180-189). O art. $5^{\circ}$ da lei fixou como "nocivos ao interêsse nacional" os atos previstos no art. $1^{\circ}$, transcrito em nota de rodapé abaixo, quando praticados por empresas estrangeiras e quando resultassem de combinações ajustadas no estrangeiro ${ }^{27}$.

23 FGV/CPDOC, AGM c s/d/29. Os entendimentos de Agamemnon Magalhães se davam sob a inspiração de Vargas, como se nota nas críticas do Presidente ao liberalismo econômico e na defesa da ação disciplinadora do Estado. Ver, e.g.: VARGAS, 1944, p. 37.

24 FGV/CPDOC, AGM c 44.04.26.

25 FGV/CPDOC, AGM c 45.04.05.

26 A associação entre direito da concorrência e desenvolvimento é feita por alguns autores, a partir de diferentes perspectivas. Ver, e.g.: PRADO, 2011; FONSECA, 2011; BERCOVICI, 2016a, p. 399-408; BERCOVICI, 2016b, p. 210.

27 “Art. $5^{\circ}$ Os atos referidos no art. $1^{\circ}$ serão considerados nocivos ao interêsse público quando: 
Não apenas o art. $5^{\circ}$ sugere um tratamento diferenciado ao capital estrangeiro, como fatores adicionais depõem nesse sentido. Agamemnon Magalhães combateu durante anos o truste de comunicação dos Diários Associados, de Assis Chateaubriand. Uma das principais razões para esse combate seria o fato de que o grupo de Chateaubriand figuraria como porta-voz no Brasil dos trustes estrangeiros, em atuação que não seria patriótica e representaria conspiração "contra os interesses da nossa economia e da nossa moral social" 28 .

Adicione-se a isso o fato de que a biografia de Delmiro Gouveia influenciou Agamemnon Magalhães, como reconhecido pela literatura (Magalhães, 1965, p. 15; (Draibe, 1975, p. 5-9; Vaz, 1993, p. 248; Forgioni, 2012, p. 102; Cabral, 2016, p. 131-132, CABral, 2020, p. 173-174). Gouveia, industrial nordestino que sofreu pressões do truste inglês Machine Cotton, morreu misteriosamente e sua indústria foi depois vendida ao capital estrangeiro. A iniciativa industrial de um brasileiro no Nordeste, levando progresso a uma região pobre, teria sido fulminada pela pressão abusiva de uma grande corporação estrangeira.

Esses elementos apontam no sentido de um nacionalismo econômico que estava presente na retórica do Estado Novo, o que indica, mais uma vez, a inserção do Decreto-Lei no 7.666/1945 num quadro econômico e ideológico mais amplo, em que inovações institucionais foram engendradas com vistas à busca dos objetivos do País, notadamente o desenvolvimento econômico nacional.

No que concerne às tipificações, o Decreto-Lei n ${ }^{\circ}$ 7.666/1945 tinha particularidades. Como atos "contrários aos interêsses da

a) envolverem indústrias bélicas, indústrias básicas, emprêsas editôras, jornalísticas, de rádio e teledifusão ou de divulgação e publicidade;

b) deles participarem emprêsas estrangeiras;

c) resultarem da ação de emprêsas nacionais ou estrangeiras, notòriamente vinculadas a coalizões, "trusts" ou cartéis, ajustados no estrangeiro".

28 FGV/CPDOC, AGM c 44.03.20/3. Ver também: FGV/CPDOC, AGM c 45.04.05; FGV/CPDOC, AGM c 45.00.00/11. 
economia nacional", no art. $1^{\circ}$ da lei, estavam previstas entre as condutas ilícitas práticas cartelizantes (inciso I) e figuras que se assemelham a atos de concentração econômica (incisos II, III e V) ${ }^{29}$.

Cotejando com dispositivos da Lei $\mathrm{n}^{\mathrm{o}} 12.529 / 2011$, nota-se, mais uma vez, o legado institucional da legislação varguista. O inciso I do art. $1^{\circ}$, do Decreto-Lei $n^{\circ} 7.666 / 1945$, aproxima-se do art. 36, $\int 3^{\circ}$, I, da Lei $n^{\circ} 12.529 / 2011^{30}$. Os incisos II, III e V do art. $1^{\circ}$, do Decreto-Lei $n^{\circ} 7.666 / 1945$, podem ser associados ao art. 90 da Lei ${ }^{\circ}$

29 “Art. $1^{\circ}$ Consideram-se contrários aos interêsses da economia nacional:

I - os entendimentos, ajustes ou acordos entre emprêsas comerciais, industriais ou agrícolas, ou entre pessoas ou grupo de pessoas vinculadas a tais emprêsas ou interessadas no objeto de seus negócios, que tenham por efeito:

a) elevar o preço de venda dos respectivos produtos;

b) restringir, cercear ou suprimir a liberdade econômica de outras emprêsas;

c) influenciar no mercado de modo favorável ao estabelecimento de um monopólio, ainda que regional;

II - os atos de compra e venda de acervos de emprêsas comerciais, industriais ou agrícolas, ou de cessão e transferência das respectivas cotas, ações, títulos ou direitos, ou de retenção de estoques de mercadorias, desde que de tais atos resulte ou possa resultar qualquer dos feitos previstos nas alíneas a, b e c do item I;

III - os atos de aquisição ou detenção, a qualquer título, de terras, por parte de emprêsas industriais ou agrícolas, em proporção superior às necessidades de sua produção, desde que daí resulte ou possa resultar a supressão ou redução das pequenas propriedades ou culturas circunvizinhas;

IV - a paralisação, total ou parcial, de emprêsas comerciais, industriais ou agrícolas desde que de tal fato resulte ou possa resultar a elevação dos preços das mercadorias ou o desemprêgo em massa de empregados, trabalhadores ou operários;

V - a incorporacão, fusão, transformação, associação ou agrupamento de emprêsas comerciais, industriais ou agrícolas, ou a concentração das respectivas cota, ações ou administrações nas mãos de uma emprêsa ou grupo de empresas ou nas mãos de uma pessoa ou grupo de pessoas, desde que de tais atos resulte ou possa resultar qualquer dos efeitos previstos nas alíneas a, b e c do item I".

30 “Art. $36[\ldots] \mathbb{S} 3^{\circ}[\ldots]$ I - acordar, combinar, manipular ou ajustar com concorrente, sob qualquer forma: a) os preços de bens ou serviços ofertados individualmente; b) a produção ou a comercialização de uma quantidade restrita ou limitada de bens ou a prestação de um número, volume ou frequência restrita ou limitada de serviços; c) a divisão de partes ou segmentos de um mercado atual ou potencial de bens ou serviços, mediante, dentre outros, a distribuição de clientes, fornecedores, regiões ou períodos; d) preços, condições, vantagens ou abstenção em licitação pública". 
12.529/2011 ${ }^{31}$. O inciso IV do art. $1^{\circ}$, do Decreto-Lei $n^{\circ} 7.666 / 1945$, pode ser relacionado ao art. 36, $\int 3^{\circ}$, XVII, da Lei n ${ }^{\circ} 12.529 / 2011^{32}$. A Lei Malaia é também responsável por instituir um controle prévio de atos de concentração avant la lettre. Operações como fusões e incorporações entre empresas de determinados setores da economia só poderiam acontecer após prévia autorização da C.A.D.E. ${ }^{33}$. Na atual lei antitruste brasileira, a Lei n ${ }^{\circ} 12.529 / 2011$, os atos de concentração somente podem ser consumados após autorização do Cade (art. 88, \ $3^{\text {o34}}$ ), sugerindo mais um legado institucional da legislação de 1945.

31 “Art. 90. Para os efeitos do art. 88 desta Lei, realiza-se um ato de concentração quando: I - 2 (duas) ou mais empresas anteriormente independentes se fundem;

II - 1 (uma) ou mais empresas adquirem, direta ou indiretamente, por compra ou permuta de ações, quotas, títulos ou valores mobiliários conversíveis em ações, ou ativos, tangíveis ou intangíveis, por via contratual ou por qualquer outro meio ou forma, o controle ou partes de uma ou outras empresas;

III - 1 (uma) ou mais empresas incorporam outra ou outras empresas; ou

IV - 2 (duas) ou mais empresas celebram contrato associativo, consórcio ou joint venture".

32 "Art. $36[\ldots] \mathbb{S} 3^{\circ}[\ldots]$ XVII - cessar parcial ou totalmente as atividades da empresa sem justa causa comprovada".

33 "Art. $8^{\circ}$ Não se poderão fundir, incorporar, transformar, agrupar de qualquer modo, ou dissolver, sem prévia autorizacão da C.A.D.E.:

a) os estabelecimentos bancários;

b) as emprêsas que tenham por objeto a produção ou distribuição de gêneros alimentícios;

c) as emprêsas que operem em seguros e capitalização;

d) as emprêsas de trensportes ferroviário, rodoviário e as de navegação marítima, fluvial ou aérea;

e) as emprêsas editôras, jornalísticas, de rádio e teledifusão, de divulgação e publicidade;

f) as indústrias bélicas, básicas, de interêsse nacional e as emprêsas distribuidoras dos respectivos produtos;

g) as indústrias químicas, de especialidades farmacêuticas ou de laboratório e de materiais odontológicos;

h) as indústrias de tecidos e calçados;

i) as emprêsas de mineração;

j) a produção e distribuição de instrumentos de trabalho, de um modo geral;

k) as emprêsas de eletricidade, gás, telefone e transportes urbanos e, em geral, os concessionários de serviços de utilidade pública".

34 “Art. 88 [...] 3을 Os atos que se subsumirem ao disposto no caput deste artigo não podem ser consumados antes de apreciados, nos termos deste artigo e do procedimento previsto no Capítulo II do Título VI desta Lei, sob pena de nulidade, sendo ainda imposta multa 
Quando de sua publicação, a Lei Malaia sofreu fortes resistências. A União Democrática Nacional (UDN), principal partido de oposição a Vargas no final do Estado Novo, alarmou no sentido de que o decreto havia causado grande tumulto, notadamente entre as “corporações econômicas" (Gomes, 1946, p. 30). O Departamento de Estado norte-americano teria interpretado a lei como "ato de nacionalismo econômico" (BANDEIRA, 1975, p. 3), provocando "ansiedade" nos Estados Unidos ${ }^{35}$. As classes produtoras nacionais - representadas pela Federação das Associações Comerciais do Brasil, pela Confederação Nacional da Indústria e pela União das Associações Agropecuárias do Brasil Central - entregaram a Vargas carta de protesto contra o Decreto-Lei no 7.666/1945 (CArone, 1976a, p. 369-377) ${ }^{36}$. A imprensa, notadamente os Diários Associados, dedicaram importantes espaços à crítica à Lei Malaia ${ }^{37}$.

De um lado, a resistência ao Decreto-Lei n ${ }^{\circ} 7.666 / 1945$ foi expressiva; de outro, essa repercussão permitiu que termos como truste, cartel, antitruste, entre outros, fossem incutidos de modo inédito no debate público. Eleito deputado constituinte na Assembleia Constituinte de 1946, Agamemnon Magalhães foi o relator do Título V da Constituição, Da Ordem Econômica e Social, e inseriu no referido título o art. 148, que estabeleceu que a lei reprimiria toda e qualquer

pecuniária, de valor não inferior a $\mathrm{R} \$ 60.000,00$ (sessenta mil reais) nem superior a $\mathrm{R} \$$ 60.000.000,00 (sessenta milhões de reais), a ser aplicada nos termos da regulamentação, sem prejuízo da abertura de processo administrativo, nos termos do art. 69 desta Lei". FGV/CPDOC, AGM c 45.03.02.

36 Ver também: FOLHA DA MANHÃ, 1945, p. 3.

37 Cf. Diário de Pernambuco, Recife, 24 jun. 1945, p. 1. O jornal chama a lei de "decretomonstro".

Ver: DIÁRIO DE PERNAMBUCO, 1945a; DIÁRIO DE PERNAMBUCO, 1945b; DIÁRIO DE PERNAMBUCO, 1945h; DIÁRIO DE PERNAMBUCO, 1945e; DIÁRIO DE PERNAMBUCO, 1945d; DIÁRIO DE PERNAMBUCO, 1945i; DIÁRIO DE PERNAMBUCO, 1945f; DIÁRIO DE PERNAMBUCO, 1945c; DIÁRIO DE PERNAMBUCO, 1945g; DIÁRIO DE PERNAMBUCO, 1945j; DIÁRIO DE PERNAMBUCO, 19451. 
forma de abuso do poder econômico que tivesse por fim dominar os mercados nacionais, eliminar a concorrência e aumentar arbitrariamente os lucros ${ }^{38}$.

Estava chancelada constitucionalmente a necessidade de uma lei especificamente antitruste, para reprimir o abuso do poder econômico. Em 1948, Agamemnon Magalhães apresentou o Projeto de Lei $\mathrm{n}^{\mathrm{o}} 122$, regulamentando o art. 148. O projeto teve um trâmite demorado, alterações relevantes e somente se tornou lei em 10 de setembro de 1962, com a Lei $n^{\circ} 4.137$, responsável pela criação do Cade. Percebe-se, com esse quadro, a importância das iniciativas legais de Agamemnon Magalhães para a criação das instituições do direito concorrencial brasileiro.

Com a iniciativa da Lei Malaia, Agamemnon Magalhães conseguiu que houvesse um debate público sobre o tema dos trustes, dos cartéis, da concentração do poder de mercado, da eliminação da concorrência e do abuso do poder econômico. Muitas das comissões, órgãos, conselhos e outras entidades criadas na Era Vargas e citadas na seção anterior são atualmente obsoletas e sequer suscitaram discussões substanciais nos anos que se seguiram. A discussão incensada por Agamemnon Magalhães sobre a necessidade de se controlar o abuso do poder econômico, porém, permaneceu e existe até hoje. Não se pode negar, nesse passo, que se tratou de relevante inovação institucional cujo legado é presentemente perceptível.

\section{CONCLUSÃO}

Os anos 1930 a 1945, notadamente no período do Estado Novo (1937-1945), produziram significativas inovações institucionais.

\footnotetext{
38 "Art. 148. A lei reprimirá tôda e qualquer forma de abuso do poder econômico, inclusive as uniões ou agrupamentos de emprêsas individuais ou sociais, seja qual fôr a sua natureza, que tenham por fim dominar os mercados nacionais, eliminar a concorrência e aumentar arbitràriamente os lucros".
} 
Diversas entidades, como comissões, institutos, conselhos, empresas estatais etc., foram criadas, assim como novas leis foram produzidas. A historiografia econômica lista a maioria dessas inovações. Contudo, não costuma incluir as legislações antitruste (como o Decreto-Lei n ${ }^{\circ}$ 869/1938 e o Decreto-Lei $n^{\circ}$ 7.666/1945), tampouco as instituições relacionadas à aplicação desses diplomas, dentre as inovações institucionais do período, havendo, assim, um silêncio de autores da relevância de Ianni, Diniz, Draibe e Fonseca sobre o tema ${ }^{39}$.

Entende-se que tais legislações devem ser consideradas inovações institucionais desse primeiro período de Vargas como Presidente. Foram iniciativas inéditas, por meio das quais o Estado tentou dar conta de problemas econômicos através de novas leis e novas instituições. Tais iniciativas se inseriram em um contexto mais amplo, em que a criação institucional servia a um propósito maior nos termos da retórica varguista, i.e., o do desenvolvimento econômico nacional. O legado institucional deixado pelas leis de 1938 e de 1945 é expressivo: desde disposições expressas previstas até hoje na atual lei brasileira de defesa da concorrência, a Lei $n^{\circ} 12.529 / 2011$, que têm dicção quase idêntica à de alguns dos dispositivos do Decreto-Lei no 869/1938 e do Decreto-Lei $n^{\circ}$ 7.666/1945, à construção de uma instituição especificamente vocacionada à repressão do abuso do poder econômico, o Cade, criada em 1962, mas herdeira da C.A.D.E., pensada em 1945 no âmbito da Lei Malaia.

Portanto, não há dúvidas de que deve ser incluída no rol de inovações institucionais da Era Vargas a legislação com conteúdo antitruste, assim como as entidades engendradas no período com a tarefa de disciplinar o poder econômico e fomentar a concorrência.

39 Com a ressalva de que Ianni cita o Decreto-Lei $n^{\circ} 7.666 / 1945$, mas ignora o DecretoLei n ${ }^{\circ} 869 / 1938$, o pioneiro (IANNI, 1977, p. 24). 


\section{REFERÊNCIAS}

ANDRADE, José Maria Arruda de. Economicização do Direito Concorrencial. São Paulo: Quartier Latin, 2014.

BAGNOLI, Vicente. Introdução ao Direito da Concorrência: Brasil globalização - União Européia - Mercosul - Alca. São Paulo: Singular, 2005.

BALZ, Christiano Celmer. O Tribunal de Segurança Nacional: aspectos legais e doutrinários de um tribunal da Era Vargas (1936-1945). Dissertação de Mestrado. Florianópolis: Programa de Pós-Graduação em Direito da Universidade Federal de Santa Catarina, 2009.

BARBIERI FILHO, Carlo. Disciplina Jurídica da Concorrência: abuso do poder econômico. São Paulo: Resenha Tributária, 1984.

BERCOVICI, Gilberto. Constituição Econômica e Desenvolvimento: uma leitura a partir da Constituição de 1988. São Paulo: Malheiros, 2005. BERCOVICI, Gilberto. Defesa da Concorrência e Proteção à Propriedade Intelectual: compatibilização entre a política concorrencial e as demais políticas públicas. In: BERCOVICI, Gilberto. Direito Econômico Aplicado: estudos e pareceres. São Paulo: Contracorrente, 2016a, p. 353-417.

BERCOVICI, Gilberto. Estado Intervencionista e Constituição Social no Brasil: o silêncio ensurdecer de um diálogo entre ausentes. In: Cláudio Pereira de Souza Neto; Daniel Sarmento; Gustavo Binenbojm. (Org.). Vinte Anos da Constituição Federal de 1988. Rio de Janeiro: Lumen Juris, 2009, p. 725-738.

BERCOVICI, Gilberto. Petrobras: monopólio estatal e política concorrencial. In: BERCOVICI, Gilberto. Direito Econômico Aplicado: estudos e pareceres. São Paulo: Contracorrente, 2016b, p. 195-213.

BERCOVICI, Gilberto; ANDRADE, José Maria Arruda de. A Concorrência Livre na Constituição de 1988. In: ADEODATO, João Maurício; BITTAR, Eduardo Carlos Bianca (Org.). Filosofia e Teoria Geral do Direito: estudos em homenagem a Tercio Sampaio Ferraz Junior por seu septuagésimo aniversário. São Paulo: Quartier Latin, 2011, p. 449-468. BOSI, Alfredo. Dialética da Colonização. São Paulo: Companhia das Letras, 1992. 
BOSI, Alfredo. O Positivismo no Brasil: uma ideologia de longa duração. In: BOSI, Alfredo. Entre a História e a Literatura. São Paulo: 34, 2013, p. 277-301.

BULGARELLI, Waldirio. Concentração de Empresas e Direito Antitruste. 2. ed. São Paulo: Atlas, 1996.

CABRAL, Mário André Machado. A Aplicação do Antitruste no Brasil: o mito da falta de efetividade da Lei de Crimes contra a Economia Popular de 1938. Nomos, v. 38, n. 2, 2018, p. 171-190.

CABRAL, Mário André Machado. A Construção do Antitruste no Brasil: 1930-1964. São Paulo: Singular, 2020.

CABRAL, Mário André Machado. Estado, Concorrência e Economia: convergência entre antitruste e pensamento econômico no Brasil. Tese de Doutorado. São Paulo: Faculdade de Direito da Universidade de São Paulo, 2016.

CABRAL, Mário André Machado. O Sentido de "Economia Popular": a origem do antitruste no Brasil nos anos 1930. Revista Eletrônica do Curso de Direito da UFSM, v. 14, n. 1, 2019, p. 1-32.

CÂMARA DOS DEPUTADOS. Diário do Congresso Nacional, Rio de Janeiro, 22 fev. 1956, seção 1, p. 1191.

CAMPOS, Francisco. A Lei de Proteção á Economia Popular. Entrevista do Sr. Ministro da Justiça, concedida a "A Noite", em 28 de novembro de 1938. In: HUNGRIA, Nelson. Dos Crimes contra a Economia Popular e das Vendas a Prestações com Reserva de Domínio. Rio de Janeiro: Livraria Jacintho, 1939, p. 187-198.

CAMPOS, Reynaldo Pompeu de. Repressão Judicial no Estado Novo: esquerda e direita no banco dos réus. Rio de Janeiro: Achiamé, 1982.

CARONE, Edgar. A Terceira República (1937-1945). São Paulo: Difel, 1976a.

CARONE, Edgar. O Estado Novo: 1937-1945. Rio de Janeiro, São Paulo: Difel, 1976b.

CARVAlHO, Vinicius Marques de. Aspectos Históricos da Defesa da Concorrência. In: CORDOVIL, Leonor et al. Nova Lei de Defesa da Concorrência Comentada. Lei 12.529, de 30 de novembro de 2011. São Paulo: Revista dos Tribunais, 2011, p. 13-30. 
DINIZ, Eli. Empresário, Estado e Capitalismo no Brasil: 1930-1945. Rio de Janeiro: Paz e Terra, 1978.

DRAIBE, Sônia. Rumos e Metamorfoses: um estudo sobre a constituição do Estado e as alternativas da industrialização no Brasil, 1930-1960. Rio de Janeiro: Paz e Terra, 1985.

FAUSTO, Boris. A Revolução de 1930: historiografia e história (1970). 6. ed. São Paulo: Brasiliense, 1979.

FERRAZ JÚNIOR, Tércio Sampaio. Lei de Defesa da Concorrência, Origem Histórica e Base Constitucional. Arquivos do Ministério da Justiça, n. 180, jul./dez., a. 45, 1992, p. 175-185.

FONSECA, João Bosco Leopoldino da. Direito da Concorrência e Desenvolvimento. Revista Brasileira de Estudos Políticos, Belo Horizonte, n. 103, jul./dez., 2011, p. 205-231.

FONSECA, João Bosco Leopoldino da. Lei de Proteção da Concorrência: comentários à legislação antitruste (1995). 2. ed. Rio de Janeiro: Forense, 2001. FONSECA, Pedro Cezar Dutra. Gênese e Precursores do Desenvolvimentismo no Brasil. In: BASTOS, Pedro Paulo Zahluth; FONSECA, Pedro Cezar Dutra (Orgs.). A Era Vargas: desenvolvimentismo, economia e sociedade. São Paulo: Unesp, 2012a, p. 21-49.

FONSECA, Pedro Cezar Dutra. Instituições e Política Econômica: crise e crescimento do Brasil na década de 1930. In: BASTOS, Pedro Paulo Zahluth; FONSECA, Pedro Cezar Dutra (Orgs.). A Era Vargas: desenvolvimentismo, economia e sociedade. São Paulo: Unesp, 2012b, p. 159-178.

FONSECA, Pedro Cezar Dutra. Vargas: o capitalismo em construção. São Paulo: Brasiliense, 1987.

FORGIONI, Paula A. Os Fundamentos do Antitruste (1998). 5. ed. São Paulo: Revista dos Tribunais, 2012.

FRANCESCHINI, José Inácio Gonzaga; FRANCESCHINI, José Luiz Vicente de Azevedo. Poder Econômico: exercício e abuso: direito antitruste brasileiro. São Paulo: Revista dos Tribunais, 1985.

FRAZÃO, Ana. Direito da Concorrência: pressupostos e perspectivas. São Paulo: Saraiva, 2017.

FURTADO, Celso. Formação Econômica do Brasil (1959). 34. ed. São Paulo: Companhia das Letras, 2007. 
GOMES, Eduardo. Campanha de Libertação. Rio de Janeiro: Livraria Martins, 1946.

HUNGRIA, Nelson. Dos Crimes contra a Economia Popular e das Vendas a Prestações com Reserva de Domínio. Rio de Janeiro: Livraria Jacintho, 1939.

IANNI, Octavio. Estado e Planejamento Econômico no Brasil (19301970) (1971). 2. ed. São Paulo: Civilização Brasileira, 1977.

LOVE, Joseph. O Regionalismo Gaúcho e as Origens da Revolução de 1930. São Paulo: Perspectiva, 1975.

LYRA FILHO, João. A Proteção da Economia Popular. Rio de Janeiro: Irmãos Di Giorgio \& Cia., 1946.

LYRA FILHO, João. Problemas de Economia Popular. Rio de Janeiro: Alba, 1939.

LYRA, Roberto. Crimes contra a Economia Popular: doutrina, legislação e jurisprudência. Rio de Janeiro: Jacinto, 1940.

MAGALHÃES, João Paulo de Almeida. Controvérsia Brasileira sobre o Desenvolvimento Econômico: uma reformulação. Rio de Janeiro: Gráfica Record, s/d.

MAGAlHÃES, Paulo Germano de. A Nova Liberdade. Combate aos trustes e cartéis. Rio de Janeiro: Tempo Brasileiro, 1965.

MAGALHÃES, Paulo Germano de. As Origens do Nome "Lei Malaia". Entrevista concedida à Secretária-Executiva do CADE. Direito Econômico: Revista do CADE, Brasília, n. 4, jan./jul., 1988, p. 11-13.

MARCOVITCH, Jacques. Pioneiros e Empreendedores: a saga do desenvolvimento no Brasil. 2. ed. São Paulo: Universidade de São Paulo, 2009, v. 1. MARTINEZ, Ana Paula. Controle de Concentrações Econômicas no Brasil: passado, presente e futuro. Revista do IBRAC, São Paulo, n. 18, jul./dez., 2010, p. 11-57.

MIOLA, Iagê Zendron. Competition Law and Neoliberalism: the regulation of economic concentration in Brazil. Direito \& Práxis, Rio de Janeiro, v. 7, n. 4, 2016, p. 643-689.

NASCIMENTO, Ruy Coutinho do. Quatro Momentos do Antitruste no Brasil. In: FARINA, Laércio (Ed.). A Nova Lei do CADE. Ribeirão Preto: Migalhas, 2012, p. 187-194. 
OLIVEIRA, Elias de. Crimes contra a Economia Popular e o Juri Tradicional. Rio de Janeiro: Freitas Bastos, 1952.

OLIVEIRA, Gesner; RODAS, João Grandino. Direito e Economia da Concorrência. Rio de Janeiro: Renovar, 2004.

ONTO, Gustavo Gomes. Da Irrelevância do Mercado ao Mercado Relevante: economistas, teoria econômica e política antitruste no Brasil. Dissertação de Mestrado em Administração Pública e Governo. São Paulo: Escola de Administração de Empresas de São Paulo/Fundação Getúlio Vargas, 2009. PEREIRA NETO, Caio Mário da Silva; CASAGRANDE, Paulo Leonardo. Direito Concorrencial: doutrina, jurisprudência e legislação. São Paulo: Saraiva, 2016.

PFEIFFER, Roberto Augusto Castellanos. Defesa da Concorrência e Bem-estar do Consumidor. São Paulo: Revista dos Tribunais, 2015.

PRADO, Luiz Carlos Delorme. Infrações da Ordem Econômica e Legislação de Defesa da Concorrência no Brasil: uma perspectiva histórica. In: FARINA, Laércio (Ed.). A Nova Lei do CADE. Ribeirão Preto: Migalhas, 2012, p. 96-123.

PRADO, Luiz Carlos Delorme. Política de Concorrência e Desenvolvimento: reflexões sobre a defesa da concorrência em uma política de desenvolvimento. Cadernos do Desenvolvimento, Rio de Janeiro, v. 6, n. 9, jul./dez., 2011, p. 321-342.

PROENÇA, José Marcelo Martins. Concentração Empresarial e o Direito da Concorrência. São Paulo: Saraiva, 2001.

RODRIGUES, Carlos Henrique Lopes. A Questão do Protecionismo no Debate entre Roberto Simonsen e Eugênio Gudin. Dissertação de Mestrado em História Econômica. Campinas: Instituto de Economia/ Universidade de Campinas, 2005.

SALGADO, Lucia Helena. A Economia Política da Ação Antitruste: o debate conceitual e um exercício para o caso brasileiro. São Paulo: Singular, 1997. SALOMÃO FILHO, Calixto. Direito Concorrencial: as estruturas (1998). 2. ed. São Paulo: Malheiros, 2002.

SHIEBER, Benjamin M. Abusos do Poder Econômico: direito e experiência antitruste no Brasil e nos E.U.A. São Paulo: Revista dos Tribunais, 1966. SILVA, Francisco Carlos Teixeira da. Os Tribunais da Ditadura: o estabelecimento da legislação de segurança nacional no Estado Novo. In: 
MARTINHO, Francisco Carlos Palomanes; PINTO, António Costa. O Corporativismo em Português: Estado, política e sociedade no Salazarismo e no Varguismo. Rio de Janeiro: Civilização Brasileira, 2007, p. 279-309. TODOROV, Francisco Ribeiro; TORRES FILHO, Marcelo Maciel. History of Competition Policy in Brazil: 1930-2010. The Antitrust Bulletin, v. 57, n. 2, 2012, p. 207-257.

VARGAS, Getulio. A Nova Política do Brasil. O Brasil na Guerra, ${ }^{\circ}$ de julho de 1944 a 30 de outubro de 1945. Rio de Janeiro: Livraria José Olympio, 1944, v. XI.

VAZ, Isabel. Direito Econômico da Concorrência. Rio de Janeiro: Forense, 1993.

\section{Documentos de arquivo}

FGV/CPDOC, A Indústria Nacional e os Trusts. Folha da Manhã, Recife, 26 abr. 1944. Arquivo Agamenon Magalhães, AGM c 44.04.26.

FGV/CPDOC, Arquivo Agamenon Magalhães, AGM c s/d/29.

FGV/CPDOC, Carta de Agamemnon Magalhães para Getúlio Vargas, 5 abr. 1945. Arquivo Agamenon Magalhães, AGM c 45.04.05.

FGV/CPDOC, Carta de João Daudt d'Oliveira a Getúlio Vargas, 20 set. 1945. Arquivo Agamenon Magalhães, AGM c 45.03.02.

FGV/CPDOC, Documentação. Folha da Manhã, Recife, 20 mar. 1944. Arquivo Agamenon Magalhães, AGM c 44.03.20/3.

FGV/CPDOC, O ABC do Truste. Núcleo Trabalhista do Partido Social Democrático. Seção de Pernambuco, 1945. Arquivo Agamenon Magalhães, AGM c 45.00.00/11.

FGV/CPDOC, Réplica de Agamemnon Magalhães a Raul Fernandes, de junho de 1945. Arquivo Agamenon Magalhães, AGM c 45.06.00/1.

\section{Matérias de jornais}

DIÁRIO DE PERNAMBUCO. O advogado Carlos Duarte depõe sobre o "Decreto Agamenon": "Faz-nos regredir aos dias mais negros do fascismo caboclo". Diário de Pernambuco, Recife, 26 jun. 1945a. 
DiÁRIO DE PERNAMBUCO. Tirania e abuso de poder. Diário de Pernambuco, Recife, 26 jun. 1945b.

DIÁRIO DE PERNAMBUCO. A economia brasileira na mesma situação da economia alemã no tempo do nazismo. Diário de Pernambuco, Recife, 27 jun. 1945c.

DIÁRIO DE PERNAMBUCO. Declara o emb. Berle: discrepa das leis dos E. U. Diário de Pernambuco, Recife, 27 jun. 1945d.

DIÁRIO DE PERNAMBUCO. Decreto-maligno - a opinião de outra fonte norte americana. Diário de Pernambuco, Recife, 27 jun. 1945e.

DIÁRIO DE PERNAMBUCO. Desaparece a propriedade privada que é uma expressão da liberdade individual. Diário de Pernambuco, Recife, 27 jun. 1945f.

DIÁRIO DE PERNAMBUCO. O ministro da Justiça ameaça começa a agir dentro de 15 dias. Diário de Pernambuco, Recife, 27 jun. 1945g.

DiÁRIO DE PERNAMBUCO. Os motivos do ódio. Diário de Pernambuco, Recife, 27 jun. 1945 h.

DIÁRIO DE PERNAMBUCO. Para intimidar os "Diários Associados". Diário de Pernambuco, Recife, 27 jun. 1945i.

DiÁRIO DE PERNAMBUCO. Repulsa geral em São Paulo. Diário de Pernambuco, Recife, 27 jun. 1945j.

DIÁRIO DE PERNAMBUCO. Sem precedentes o pánico na Bolsa. Diário de Pernambuco, Recife, 27 jun. 19451.

FOLHA DA MANHÃ. Manifestam-se as classes produtoras sobre o decreto-lei 7.666. Folha da Manhã, São Paulo, 25 jul. 1945, Caderno Único, p. 3.

\section{MÁRIO ANDRÉ MACHADO CABRAL}

Doutor em Direito Econômico pela Universidade de São Paulo (USP). Atualmente é pesquisador no Engelberg Center on Innovation Law \& Policy da Universidade de Nova York (NYU). 
Endereço profissional: 40 Washington Square S, New York, NY 10012, United States of America.

ORCID ID: https://orcid.org/0000-0001-6113-7287

E-MAIL: marioandremc@gmail.com; mac10028@nyu.edu

Recebido: 01/11/2020

Aceito: 05/09/2021

\section{(c) $\underset{\mathrm{BY}}{(-)}$}

Este trabalho está licenciado sob uma licença Creative Commons Attribution 4.0 International License.

Autores e autoras cedem à Revista Sequência direitos exclusivos de primeira publicação, ficando o trabalho licenciado sob a Creative Commons Attribution 4.0 International License. A licença autoriza que terceiros remixem, adaptem e ou criem a partir do trabalho publicado, indicando o crédito ao trabalho original e sua publicação inicial. Os autores têm permissão para assumir contratos adicionais em separado, com distribuição não exclusiva da versão publicada na Revista Sequência, indicando, de todo modo, a autoria e publicação inicial neste periódico. 